\title{
LA DESTRUCCIÓN DEL ROSTRO Y DE LA IDENTIDAD EN EL DESIERTO Y SU SEMILLA DE JORGE BARON BIZA
}

Resumen: El ataque contra el rostro de la mujer amada y perdida que se recupera en el relato de El desierto y su semilla de Jorge Baron Biza, permite reflexionar sobre las formas y mecanismos de construcción de la identidad en dicha novela y en nuestra cultura. El lugar del cuerpo, del rostro, de la personalidad y la singularidad de cada ser humano. A su vez, se pretende establecer vinculaciones con la pintura de Arcimboldo para comprender el porqué de las referencias que circulan en el texto en relación con sus cuadros.

Palabras clave: Baron Biza, Rostro, Identidad, Desierto, Semilla.
Federico G. Ferroggiaro

Universidad Nacional de Rosario

fgferroggiaro@yahoo.com.ar

\begin{abstract}
The assault against the countenance of the beloved and lost woman retrieved in the account "The dessert and it's seed", by Jorge Baron Biza, allows the reader to reflect upon the patterns and mechanisms of identity building in such novel and in our own culture in general; instead of focusing in the body, the face, the personality and the singularity of every human being. Likewise, it means to stablish relations between Arcimboldo's paintings, to become aware of the meaning of the references that underlie the story with respect to his pictures.
\end{abstract}

Keywords: Baron Biza, Visage, Identity, Desert, Seed. 
La premisa para comenzar sería que no interesa reconocer la relación entre la narración que propone la novela El desierto y su semilla y la oscura crónica familiar de los Baron Biza - Sabattini. No, no interesa, no hace a la cuestión. Ni el hecho policial ocurrido en 1964, ni la fácil equiparación de Mario, el narrador, con Jorge Baron Biza, el nombre que encabeza la tapa del libro: el autor.

Además, sobre el particular, la gran mayoría de los trabajos críticos sobre la obra recalan o consideran ineludible este aspecto. Alan Pauls, en "Jorge Baron Biza, el hombre del subsuelo", la califica como "la autobiografía de un sobreviviente" que sufre y manifiesta en su escritura que su propia vida "no es mucho más que un despojo, el excedente de una experiencia protagonizada por los que le dieron la vida" (Pauls, 2012, párr. 5). Por su parte, María Soledad Boero, afinando las herramientas que ofrece la teoría, la inscribe como una variante de la autoficción. "En la obra encontramos desplegados una serie de procedimientos autoficcionales que van desde los elementos paratextuales más visibles [...] hasta los juegos con el nombre propio y con las "fuentes" que aparecen detalladas al final de la obra" (Boero, 2008, p. 21). El pacto de lectura ambiguo que propone el género autoficcional, en el cual la veracidad y la referencia autobiográfica ceden su prominencia "a una experiencia de escritura encargada de reconstruir la identidad de un yo que se ha vaciado de sentido" (Boero, 2008, p. 21), le sirven de fundamento a Boero para sostener esta relación entre los hechos ocurridos, y documentados, y la creación literaria. Nora Domínguez, que se ocupó de El desierto y su semilla al trabajar el rostro en $D e$ donde vienen los niños, apunta en un artículo, "Hechos, derechos y teorías", que esta novela 
"reconstruye ese relato familiar dispersando otros nombres y manipulando los datos de la historia verdadera según los recursos de la ficción literaria" (Domínguez, 2011, párr. 1). Hasta el prólogo a la edición que utilizamos, escrito por Nora Avaro, comienza narrando con rigor periodístico el caso policial. Es decir, tanto en las reseñas como en las lecturas críticas, la en este caso indiscutible simbiosis "realidad" - ficción, operan como un punto de foco inevitable.

Por todo esto, nos quedamos en la ficción, nos importa aquello que el relato construye a partir de los ataques contra el rostro y el análisis que sobre ellos puede proponerse. No los hechos "reales" sino su transustanciación en el lenguaje, en el marco de la narración. “'Lo que sucede' en el relato no es, desde el punto de vista referencial (real), literalmente nada; 'lo que pasa', es sólo el lenguaje, la aventura del lenguaje, cuyo advenimiento nunca deja de ser festejado" (Barthes, 1977, p. 101).

Nos informa el prólogo de la edición del 2013 de Eterna Cadencia que El desierto y su semilla se publicó en una edición de autor, en 1998, luego de presentarse, sin éxito, al Premio Planeta. La novela narra el lento proceso de demolición y reconstrucción del rostro de Eligia, la madre del narrador, luego de que este fuera devastado por los ácidos que le arroja su marido: Arón Gageac. Este ataque no puede ser contado por el hijo - narrador en una secuencia ordenada, sino que se reconstruye de manera fragmentaria a lo largo del texto. De hecho, el relato comienza luego de que se consumó la agresión y la primera mención de la misma es tangencial, para, más 
adelante, ir agregando la información que permite integrar los detalles de cómo se produjo. Recién en el segundo capítulo se describe el lugar donde ocurre el ataque y, en el quinto, el contexto en el que se produce: el divorcio definitivo de Arón y Eligia. Es posible que el trauma, que la violencia del acontecimiento y el vínculo del narrador con los protagonistas del incidente, obturen la posibilidad de dar cuenta del mismo de forma lineal y completa. $\mathrm{O}$, también, que el suceso en sí sea secundario en relación con el tema central de la novela que es el movimiento que va de la pérdida a la recuperación del rostro que fue demolido.

Porque no se trata de un ataque contra un rostro otro, sino contra el rostro del Otro. El rostro que ataca Arón Gageac no es un rostro cualquiera, de cualquier otro, sino del Otro amado con quien se está poniendo el fin legal de un amor retorcido, de ese "amor - odio" que se describe en el capítulo quinto. Un rostro conocido, deseado, en el cual se leyeron las facciones del placer y del sufrimiento al que ese Otro amado fue sometido. Para la economía de la narración y a partir de los rasgos que definen a los personajes -su relación oscilante durante 28 años, la génesis del matrimonio entre ambos (Eligia es la hija del gobernador que encarcela a Arón por una supuesta conspiración en su contra) - la agresión adquiere múltiples sentidos. La voluntad del agresor era dejar ciega a la agredida: Arón quería que la última imagen que viera Eligia fuera la de él lanzándole el ácido sobre el rostro y los ojos. No el asesinato, que supone la eliminación del otro; ni la castración, que implica la pérdida de la posibilidad del placer sexual con otro, sino el borramiento 
del rostro y congelar en las retinas de la víctima a su victimario en el momento definitivo del ataque.

En esta dirección, nos parece pertinente la reflexión de Boero que asegura: "la materialidad de ese rostro materno - a través de su silencio- es el verdadero protagonista de la narración" (Boero, 2008, p. 24) porque "la herida provocada por el ácido en el rostro materno comienza a operar otra génesis en la cara" (Boero, 2008, p. 25) en la cual la carne, materia que se transforma con la alquimia de la persistencia del líquido arrojado, sin el velo de la piel, deja a la vista sus impresionantes metamorfosis que son, la "carne" de lo que narra la novela.

A partir de lo antedicho, una de las preguntas que puede plantearse es acerca de los efectos que produce la pérdida del rostro en el damnificado. Es necesario, entonces, en primer lugar, definir qué se entiende por rostro y, luego, qué posiciones ocupa éste en "nuestra cultura" -en un sentido general-, en la conformación de la identidad del "yo para los otros" y del "yo para mí" y de cómo esta identidad se descompone y deshumaniza con la pérdida del rostro como soporte del "yo" frente a la mirada ajena. Al mismo tiempo, trazar un recorrido por la novela, que es nuestro objeto, para señalar los tratamientos que recibe el tema.

Durante el largo devenir del pensamiento filosófico para tratar de definir y explicar al sujeto, al "yo", se registra un pasaje de la subjetiva autoconciencia -instaurada a partir del razonamiento cartesiano- a la búsqueda de una expresión exterior y concreta que sea la inobjetable manifestación de la (una) personalidad. En este 
movimiento, a finales del s. XIX, se asume que, mientras el cuerpo es la certeza de un alguien, y parte de su identidad, solamente el rostro se constituye en la expresión de un sujeto. Para completar, al menos parcialmente, esta marcha acerca de las ideas sobre el sujeto, se torna fundamental el aporte de Levinas que "reconoce también en el rostro una manifestación de la persona entera, de un absoluto que es cada sujeto" (Bosch, 2004, p. 114) y permite así "el paso decisivo y definitivo para reconocer el cuerpo como identidad: el rostro, corpóreo, manifiesta a alguien, una personalidad, un sujeto" (Bosch, 2004, p. 114). De esta manera, se es en tanto una materialidad que existe para y ante la mirada del otro. Señala Butler:

El yo encuentra no sólo tal o cual atributo del otro, sino el hecho de que este otro está fundamentalmente expuesto, es visible, se lo ve y existe de manera corporal y necesaria en un ámbito de la apariencia. Esa exposición que yo soy constituye, por decirlo de algún modo, mi singularidad. (Butler, 2009, p. 51)

Singularidad que se manifiesta y expresa en el rostro, en la experiencia del encuentro con el rostro del otro que es autónomo y autosuficiente. En las palabras de Levinas:

Lo que llamamos rostro es precisamente esa presentación excepcional, presentación de sí por sí mismo, sin medida común de la presentación de realidades simplemente dadas, siempre sospechosas de alguna superchería, siempre posiblemente soñadas. (Levinas, 2002, p. 216).

No se pretende desestimar o menospreciar la importancia del cuerpo separado del rostro. Cuerpo que, en "nuestra cultura", permanece casi siempre y casi en su totalidad, oculto bajo la vestimenta y su aparente homogeneidad -a pesar de su variedad que distingue sexo, 
clase social, condición laboral, entre otras - impuesta por los usos, los hábitos y las modas, que tapan las señas particulares que facilitarían, no ya la expresión de lo humano, sino la identidad de un determinado sujeto: otro reconocible no ya como "otro" cualquiera, sino como un "otro-tal". De esta forma, lo que se ofrece a la mirada del otro, lo que se ofrece desnudo y pleno, sin velos ni máscaras que lo mezquinen, es el rostro. $\mathrm{Y}$ a partir de la visión del rostro ajeno, el otro (y el "yo") es capaz de reconocer la presencia y la existencia de un "otro" que comparte y coincide en su status humano.

Así, el ser humano no puede entenderse ni ser entendido sino en una compleja red de relaciones, constituidas por miradas que se entrecruzan con otras, en un entorno amueblado por signos identitarios de diverso orden y registro, por la fisonomía del rostro, por el acento de un gesto facial (Vásquez Rocca, 2008, p. 222).

Más allá, por ejemplo, de la temprana especulación pirandelliana, recuperable en su plenitud y su madurez en la novela Uno, nessuno e centomila (1924), que postula la falta de univocidad de un rostro, el de Vitangelo Moscarda, en particular y el de todos, en general, ante la mirada de los distintos "otros". Lo cierto parecería ser que el rostro, aunque sea uno distinto para cada observador, transmite igual la seguridad de la presencia o del estar frente a un sujeto, frente a otro. La pregunta, que podría ser dirigida a un fisonomista, podría formularse de la siguiente manera: ¿qué hace que un rostro se defina como humano? La posibilidad de expresar su humanidad, su pertenencia al género. Y dicha expresión, necesariamente, requiere de un soporte concreto, con una forma determinada. El sujeto privado de su rostro, como es el caso de Eligia después del ataque, aunque posea un cuerpo, adolece de incompletud porque carece de las señas distintivas de lo humano. En su 
informidad, impide la identificación, el reconocimiento; no de alguien en particular, sino de un otro humano.

Borrar el rostro, en definitiva, es anular cualquier posibilidad de ser reconocido por el otro porque si el otro es quien configura y da existencia al yo, desaparece así la posibilidad de ser para el otro y de ser en el espejo. Queda el cuerpo, es cierto. Pero el cuerpo es contorno, una masa con señas propias muy finas, que demandan un esfuerzo mayor para ser identificado a primera vista. En las morgues, los cuerpos sin rostro deben ser peritados por un familiar cercano, por alguien que conocía al occiso de forma íntegra. Y son, justamente, las marcas, las anomalías del cuerpo las que permiten el reconocimiento: lunares, cicatrices, deformaciones, mutilaciones; en definitiva: todo aquello que hace a ese cuerpo distinto a los demás cuerpos.

En El desierto y su semilla puede leerse el proceso de este tipo de pérdida. El narrador se presenta como un testigo privilegiado de las transformaciones que experimenta el rostro de Eligia. En el primer momento, asiste a la descomposición que provocan los ácidos y, luego, al vaciamiento que se realizan en las cirugías para detener los efectos que estos continúan produciendo. Los cambios se suceden: aparecen colores, "hinchazones", formas frutales, florecimientos. "En el fondo de los pozos que cavaban los médicos, reaparecían cada mañana, después del quirófano, los colores alegres del primer día, los colores de las heridas frescas, que delataban vida y prometían curación" (Baron Biza, 2013, p. 31). Aparte de las formas definidas, el rostro carece de estabilidad y, por lo tanto, de toda posibilidad de reconocimiento. Los injertos que se aplican detienen esa 
explosión de vitalidad, ralentizan el caos y mineralizan carne. "La transformación de la carne en roca tapó los colores brillantes [...] El ataque de Arón convertía todo el cuerpo de Eligia en una sola negación, sobre la que no era fácil construir sentidos figurados. La fertilidad del caos la abandonó" (Baron Biza, 2013, p. 33). Lo último en caer en la demolición es la nariz, lo único artificial que integraba el rostro, fruto de un retoque estético de la juventud. Retirado ese hito se termina con el proceso de desmontaje del rostro iniciado por Arón y completado por los médicos. Y entonces, con los parches que ocultan los estragos y la posible regeneración, lo que queda es la ausencia de sentidos, de significantes, la "negación" que enuncia Mario, el fin de las metáforas. No hay rostro, hay piedra. "La identidad del otro es su rostro que, en sus movimientos, permanece" (Mandoki, 1992, p. 180). El de Eligia fue arrasado y oculta su destrucción bajo una lápida de injertos que la privan de una identidad para los otros desconocidos y, además, por la misma causa, le quitan su estatuto humano. Por eso, al partir rumbo a Milán donde se completará la obra iniciada en Buenos Aires, el niño que en la cabina del avión se encuentra con esta imagen le pregunta a su madre: “¿Qué es? ¿Qué es?” (Baron Biza, 2013, p. 52), interroga en busca de una definición sobre lo desconocido: un cuerpo humano donde falta el rostro. La respuesta, lógica y esperable ante el asombro y lo extraño, es "No mires, no mires", como ordena esa madre, porque todo aquello que no se ve puede no existir, negarse en su negación, porque un humano sin rostro es algo difícil de concebir y aceptar. Y si en el niño eso estimula la curiosidad, el adulto prefiere suspender las dudas apartando la mirada. 
Incluso, a la vez, ese vacío que el narrador ve en donde estaba el rostro y que, en el mismo acto, lo "mira", observa María Soledad Boero, el narrador se constituye. "Podemos suponer que el narrador experimenta su propia pérdida, su propio vacío, y todo lo que ve estaría marcado por la pérdida del rostro materno" (Boero, 2008, p. 23).

En la clínica del profesor Calcaterra, Eligia se abandona esperanzadamente a las vicisitudes de esa nueva etapa del tratamiento. El médico jefe anuncia que continuará quitando la carne quemada y la estructura dañada para permitir la reconstrucción sobre bases firmes y sanas. En su exposición sobre el devenir de la curación, el supuesto que atraviesa el discurso, es que debajo de la piel, debajo de la superficie que se da a la mirada, existen unas fuerzas, una potencia irrefrenable que debe ser controlada para que emerja, para que se manifieste la "verdad". "Señora, cavaremos en busca del Creador", le informa el doctor Calcaterra, "a partir del odio que la ha herido $[\ldots]$ encontrará la su grande verdad (sic) [...] el desollamiento por quemadura tiene su aspecto razonable: descubrir la belleza interior" (Baron Biza, 2013, p. 75). La presunción de una interioridad remite a la existencia de algo que es verdadero en el ser y que, como tal, se encuentra escondido a los ojos del otro. El rostro, de esta manera, se convierte en una máscara que oculta la "verdad" que, en el caso de Eligia, tras la destrucción y desaparición de ésta, permite asistir al movimiento del "caos" que engendrará su "verdad".

Durante este periodo en Milán, en una actitud que está en consonancia con la situación que está viviendo, el narrador observará todo lo que lo rodea guiado por una 
pregunta implícita, que podría esbozarse de este modo: ¿qué es lo que puede verse bajo la apariencia primera, bajo lo que está dado a la vista de quien mira? Es por eso que en el prólogo, Nora Avaro hace notar, atinadamente, que:

La descripción a distancia pero en detalle -incluso en algunos de sus detalles naturalistas y estetizantes que figuran, para Baron Biza, un particular sino decandentista- sea el área de realizaciones más pujantes de El desierto y su semilla: la cara de Eligia como paradigma, pero además, el cuarto de la clínica, las calles, un zaguán, el jardincito, la neblina y la fachada de la Universidad de Milán; el cuadro El jurisconsulto de Arcimboldi; las arquitecturas de las iglesias, los cementerios, las colinas, la llanura de un trayecto italiano... (Avaro, 2013, p. 13).

Así como el rostro en convulsión, todo es sometido a una exploración que busca adentrarse, penetrar, traspasar el aspecto exterior para ver de qué están hechas las cosas, cómo están hechas. Muchos pasajes de la novela recrean, a partir de distintos objetos, esa dinámica de la recomposición del rostro de Eligia, extendiendo la comparación a diversos territorios en donde se pone en juego la relación entre las partes que componen al todo para dar a ese conjunto una apariencia de identidad que lo torna reconocible para la mirada del otro. Hasta el avión que llevó al narrador y a su madre a Milán, después del viaje, se presenta como si fuera una dama desollada que se deja hacer la toilette. Veía partes del fuselaje levantadas, que mostraban interiores metálicos, fácilmente reemplazables; señores con uniformes multicolores que conectaban cables y caños a extrañas máquinas resopladotas que parpadeaban con sus manómetros (Baron Biza, 2013, p. 62). 
La "verdad" del avión sale a la luz para que el narrador pueda describir lo que subyace a la apariencia, el reverso de la forma completa que se muestra, las partes que se esconden detrás del exterior.

En esta línea de indagación, nos resulta paradigmática la mención y el análisis que, páginas más adelante, el padre de una adolescente, Sandie, a la que Mario conoce en la clínica, realiza sobre el cuadro de Giuseppe Arcimboldo que adorna el comedor de su elegante departamento en Corso Magenta. Se trata de El jurisconsulto, una de las célebres Cabezas Compuestas del pintor milanés.

Arcimboldi descubrió que la yuxtaposición, la falta de perspectiva y de escala, desnudan la carne mucho más que todas esas reflexiones tan racionales. Con perspectiva, solo hay copia de la naturaleza; solo la falta de escala permite la mezcla de carnes, la expresión de la irracionalidad de cada ser, que así, por ausencia de normas, se convierte en carne disponible para el tenedor o el cañón (Baron Biza, 2013, p. 120).

Plantea el hombre, un comerciante acomodado que añora los buenos tiempos del fascismo, explicando la idiosincrasia milanesa contra el idealismo florentino, y el sentido de la lógica compositiva de Arcimboldo. La inclusión de este cuadro en el relato, justo cuando Eligia atraviesa "el periodo más descarnado de su tratamiento" (Baron Biza, 2013, p. 100), con los huesos mostrándose ostensiblemente, cubiertos apenas por una fina cutícula, nos permite reponer una comparación entre el proceso de creación artística en la obra pictórica, con el que realiza la naturaleza, bajo la supervisión médica, en el interior del 
rostro de Eligia. Respecto al primer término, Roland Barthes observa que: "Su pintura tiene un trasfondo de lenguaje, su imaginación es plenamente poética: no crea signos, los combina, los permuta, los desvía" (1986, p. 134). Arcimboldo trabaja sus Cabezas Compuestas con formas que ya existen, definidas, completas y reconocibles. Pollos, la cola del pez, los expedientes o legajos "son ya objetos con un nombre, es decir, en palabras..." (Barthes, 1986, p. 138). Así, en la lectura de Barthes, "Arcimboldo fabrica lo fantástico a base de lo muy conocido: el todo tiene un resultado distinto a la suma de las partes: más bien parece una resta" (1986, p. 144). Significantes que se acoplan, que se reúnen, que se saturan en una forma nueva: los pollos y los peces que componen el rostro del jurisconsulto.

El parangón es inevitable. Aunque el procedimiento, en ambos casos, sea semejante -descomposición de las partes, sumatoria, nueva forma- los resultados acaban manifestándose de manera opuesta. El rostro de Eligia es todo lo contrario de las Cabezas de Arcimboldo: sus partes no son significantes definidos y la sumatoria de ellos, informes, produce así mismo lo indefinido y amorfo; es sustancia, sí, pero sustancia sin sentido. Y aquello que en Arcimboldo es combinación y alegoría, en ella es la imposibilidad de la metáfora, imposibilidad de figuraciones, un no-rostro cuyo interior es el caos en movimiento.

Podemos afirmar que todas las descripciones -o exploraciones- de los lugares y sus interiores mencionados por Avaro pueden ajustarse a la dinámica compositiva que se señalaron para el cuadro de 
Arcimboldo. En todos ellos puede percibirse el modo en que los elementos significantes se reúnen, se agrupan, conformando una realidad concreta y reconocible para el observador que realiza en los mismos una operación de desmontaje. Al final de ese recorrido, Mario consigue enunciar la forma en que trabaja Dios: con lo casual, con lo heterogéneo, y cotejar ese descubrimiento con lo que sucede en el rostro en recomposición de su madre. "Dios no puede ser algo tan delicado como el vacío ni tan simple como lo inconfundible. A él le sirven todos los materiales, hasta los deberes mal hechos y las narigonas" (Baron Biza, 2013, p. 163).

Antes de regresar a Argentina, finalizado el trabajo del doctor Calcaterra con Eligia, Mario asiste a la despedida con la prostituta "conversa", Dina, la mujer que lo acompañó durante los recreos nocturnos y las borracheras en Milán. Remedando el acto paterno, en ese encuentro, Mario atentará contra el rostro de Dina. En su caso, se trata de una imitación en miniatura y muy desmejorada de aquel acto resuelto con espectacularidad por parte de Arón. El ambiente, los espectadores o testigos, el gesto de servir las bebidas y lanzar los ácidos perfectamente preparados y combinados para su objetivo devastador, convierten el ataque en una cuidada puesta en escena que se corona, luego, con el suicidio del victimario. Aquí, en cambio, Mario, a traición y en privado, corta el rostro de la mujer para vengar la estafa fundadora, ocurrida veinte meses antes en la cronología del relato, que selló su vínculo con ella. Al menos, de esa manera justifica el narrador el ataque al preguntarle cuánto le habían dado de 
comisión "con la historia de l'etto" (Baron Biza, 2013, p. 197).

El ataque de Mario no pretende destruir un rostro y, con él, su identidad. No busca congelar su imagen en el otro, ni quitarle a la víctima la posibilidad de ser para los otros. A Arón lo impulsó el amor - odio, la pasión, mientras que el sentimiento del narrador hacia Dina es resumido como "la cualidad que más me atraía en ella resultaba precisamente esa evanescencia nocturna que me liberaba de todo compromiso" (Baron Biza, 2013, p. 193) $\mathrm{y}$, por lo tanto, lo que el padre había sido una agresión contra el Otro amado, en Mario se percibe como una lucha, un deseo de rebelarse contra la apariencia de completud y armonía que presenta un otro.

Hasta entonces, durante el tiempo que coincidieron en el bar y en las aventuras derivadas del oficio de ella, Mario afirma que se había acostumbrado a observar fragmentos -el brazo, el codo, la piel parcelada- de Dina, abstrayéndose del conjunto. Recién ahí, en la entrevista final, "miré por primera vez su cuerpo como una totalidad" (Baron Biza, 2013, p. 195) y, frente a la desnudez de la mujer, contemplada en su conjunto, "La miré con detenimiento: una cara que sostenía su presencia [...] y lograba el equilibrio con el cuerpo" (Baron Biza, 2013, p. 194), comprende el modo en que todas las partes o fragmentos se acoplan para integrarse en una unidad: "Así supe que la belleza es totalidad, continuidad que se desarrolla en todas las posibilidades" (Baron Biza, 2013, p. 196). Es un momento epifánico, pero incómodo. Porque vuelto a descomponer el cuerpo y el rostro, la imperfección resurge patente, innegable: 
No estaba frente a un cuerpo perfecto y suspendido fuera del tiempo: llevaba una cicatriz de vacuna; tenía demasiado marcados los abdominales, por causa de su trabajo; la ropa interior dejó una línea de color rosa viejo apenas por debajo del ombligo; le habían salido callos en los pies... (Baron Biza, 2013, p. 197).

Desoyendo el mandato ético que Levinas instala en el rostro, el imperativo del "no matarás" que enuncia la tentadora precariedad del rostro del otro, Mario corta un pómulo y otra parte de la cara de Dina. Ve el interior, el hueso, y emerge la sangre y, ante la sorpresa de ella, lanza el justificativo, la venganza, que esconde la razón que suponemos cierta: que Mario no puede resolver la dicotomía sobre la identidad del yo; de si el yo es el todo, el conjunto, o ese conglomerado de partes disociadas, de fragmentos autónomos. Esa oscilación entre la apariencia y la verdad lo impulsa a una reacción violenta. La cita que incluye de "su" Nietzche condensa este desconcierto: "tu cuerpo no dice yo mas actúa como yo" (Baron Biza, 2013, p. 197).

De hecho, páginas antes, la tía de Dina, una mujer fogueada por los horrores de la II Guerra Mundial, define al rostro como "sagrado" y agrega: "La cara es para recibir a los otros $[\ldots]$ para que los hombres puedan conocerse a fondo entre ellos [...] si no amas, la cara de tu prójimo se convierte en bisteca, en algo temible" (Baron Biza, 2013, p. 191 y 192). Por eso Mario puede vulnerar ese espacio que, por falta de amor, por indiferencia, es un territorio que puede ser ultrajado.

Dos modos diferentes de atacar el rostro se presentan en El desierto y su semilla, de Jorge Baron Biza. Como hemos señalado, en el caso de Arón - Eligia, se percibe un 
intento de borrar la identidad y la misma humanidad a través de la destrucción del rostro. Claramente, no se trata de un rostro cualquiera sino aquel que, como se señaló, recuerda y simboliza el tortuoso recorrido de una relación amorosa extrema, en los límites. La supervivencia deshumanizada, sin posibilidad de ser reconocido por los otros, convierte a la víctima en una nulidad absoluta, en la negación de la existencia en los términos de poder distinguir las marcas del yo en el rostro que ha devenido en un no- rostro. Prueba de esto es que, en su regreso a la actividad política, Eligia padece, a pesar de la reconstrucción, la pérdida de su rostro que ha recuperado pero que ya no puede ser el que ha sido, para lo demás. En el libro anteriormente mencionado de Nora Domínguez, podemos leer: "El rostro, espejo por excelencia de lo humano, deviene vacío, abismo, páramo. La destrucción del rostro concierne a la destrucción de las funciones sociales que él refleja y contiene" (Domínguez, 2007, p. 473).

En segundo lugar, en la relación Mario - Dina, el ataque adquiere un cariz distinto. Ya sea como deseo de venganza contra un objeto intercambiable en la serie, o bien como la repetición degradada de un mandato familiar, la correspondencia se presenta como irrefutable. Si el ataque de Mario contra el Eligia repercute, para el narrador, en la disolución o vaciamiento de su propia identidad -ya no es a los ojos mirada de su madre-, la acción restauradora, simbólica y material, que acomete contra el rostro de Dina, lo instala en un terreno de afirmación en el cual se constituye en verdugo frente a otra mirada femenina. Desde los compadritos y los proxenetas, la marca del 
hombre en el cuerpo de la mujer, como en el de los animales, constituye otro de los vergonzosos peldaños que concluyen en la repugnante excusa del femicida: "la maté porque era mía". "El cuerpo femenino, por su contigüidad con la noción de territorio, tiene la función de soportar esos avances violentos sobre los cuerpos de las mujeres" (Domínguez, 2011, párr. 5). En este caso, entendemos, se trata de un intento por borrar en otro cualquiera la angustiante incomprensión acerca de cómo se compone la identidad, el inextricable juego entre las partes y el todo.

\section{Referencias bibliográficas}

Avaro, N. (2013). Prólogo. En Baron Biza, Jorge. El desierto y su semilla. (pp. 7 - 16). Buenos Aires: Eterna Cadencia.

Baron Biza, J. (2013). El desierto y su semilla. Buenos Aires: Eterna Cadencia.

Barthes, R. (1977). El análisis estructural de los relatos. En Silvia Niccolini (comp.). El análisis estructural. Buenos Aires: CEAL.

---. (1986). Arcimboldo o El retórico y el mago. En Lo obvio y lo obtuso. Imágenes, gestos, voces. Barcelona: Ediciones Paidós Ibérica SA.

Boero, M. S. (2008). Sobre rostros caídos: la construcción de una estética en El desierto y su semilla, de Jorge Baron Biza. En Cartaphilus 3. Revista de Investigación y Crítica Estética, 20-30. Recuperado de: https://revistas.um.es/cartaphilus/article/view/23441

Bosch, M. (2004). Cuerpo e identidad. En Thémata. Revista de Filosofía. Núm. 33 111-116. Recuperado de: 
http://institucional.us.es/revistas/themata/33/10\%2obo sch.pdf

Butler, J. (2009). Dar cuenta de sí mismo. Violencia ética y responsabilidad. Buenos Aires: Amorrortu editores.

Domínguez, N. (2007). De dónde vienen los niños. Maternidad y escritura en la cultura argentina. Rosario: Beatriz Viterbo.

---. (2011). Hechos, derechos, teorías. En Cuadernos del Inadi. Núm. $4 . \quad$ Recuperado de: http://cuadernos.inadi.gob.ar/numero-04/noradominguez-hechos-derechos-teorias/

Lévinas, E. (2002). Totalidad e infinito. Ensayos sobre la exterioridad. Salamanca: Ediciones Sígueme.

Mandoki, K. (1992). Estética de la identidad y sus paradojas. 165-182. Recuperado de: http://148.206.107.15/biblioteca_digital/articulos/7139-2108wpg.pdf

Pauls, A. (2012). Jorge Baron Biza, el hombre del subsuelo. Recuperado de: https://www.letraslibres.com/mexicoespana/jorge-baron-biza-el-hombre-del-subsuelo

Pirandello, L. (2015). Uno, ninguno y cien mil. Buenos Aires: Losada.

Vásquez Rocca, A. (2008). Sloterdijk; entre rostros, esferas y espacio interfacial. En Eikasia. Revista de Filosofía, año III, número 17, 221-235. Recuperado de: http://revistadefilosofia.com/17-05.pdf

Fecha de recepción: 05/03/2018

Fecha de aprobación: 11/12/2018 